http://jmscr.igmpublication.org/home/

ISSN (e)-2347-176x ISSN (p) 2455-0450

crossref DOI: https://dx.doi.org/10.18535/jmscr/v7i9.03

\title{
To Study MRI Changes in Severely Anemic Children (0-3 Years)
}

\author{
Authors \\ Dr Parminder Kaur, Dr Parveen Mittal \\ Government Medical College, Patiala \\ *Corresponding Author \\ Dr Parminder Kaur
}

\begin{abstract}
This observational study was done on 25 severely anemic children aged 0-3 years admitted in the emergency department of GMC Patiala. The aim of the study was to study MRI changes in these children. The classification was done according to type of anemia, neurological changes and MRI findings. Cortical atrophy (table 1) was found to be in 15 out of 25 cases of severe anemia which accounted for $60 \%$ of the cases. (table 2). 14 cases out of total children with cerebral atrophy had dimorphic anemia accounting for $56 \%$ cases. (table 3 ).

Keywords: severe anemia, cerebral atrophy, neurological finding, dimorphic anemia.
\end{abstract}

\section{Introduction}

According to NFHS3 $79 \%$ of Indian children have anemia (71\% urban, $84 \%$ rural). Prevalence of anemia globally in children $0-3$ years group was found to be $47.4 \%$. Anemia is defined as when Hemoglobin concentration is more than $2 \mathrm{SD}$ below the mean for age and sex. According to WHO in 0-3 years cut off Hemoglobin for defining anemia is $11 \mathrm{gm} .{ }^{[1]}$

The $\mathrm{Hb}$ level at which sign symptoms of anemia develop depends on the rate of development of anemia. The manifestations vary from irritability, skin, mucosa changes, stomatitis, hyper pigmentation of skin on knuckles, HSM, neurological features. Early neurological features are hypotonia, developmental delay, seizures, loss of position, vibration, sensory deficit, memory loss. The neurological abnormality can develop in absence of hematological abnormality in case of Vit B12 deficiency ${ }^{[2]}$. Infantile tremor syndrome, neuropathy (cerebral atrophy), blindness (optic atrophy) are consequences of Vit B12 deficiency. Vit B12 deficiency in infants is most often nutritional due to low cobalamine levels in breast milk of Vit B12 deficient mother ${ }^{[3]}$.

\section{Aims and Objectives}

To study MRI changes in cases of severe anemia in children 0-3 year's age group.

\section{Material and Methods}

This study was done on 25 severely anemic children age group 0-3 years. They were classified according to age, sex, type of anemia, any neurological finding and development abnormality. Further MRI studies were done. All this data was collected and the cases with cerebral atrophy were recorded.

\section{Inclusion Criteria}

- Children 0-3 yrs age with 
- Severe Anemia (Pallor)

- Seizures

- Infantile Tremor Syndrome

- Developmental Delay

- Regression of Milestones

- Any Other Neurological Finding

\section{Exclusion Criteria}

- More than 3 years old

- Children with neurological findings attributed to cause other than anemia as malformations, metabolic causes.

\section{Discussion}

Out of 25 severely anemic children grouping was done as follows. 11 were male children and 14 were female. According to age they were classified as under

\begin{tabular}{|l|c|}
\hline$<1$ year & 12 ( no of children) \\
\hline $1-2$ years & 10 \\
\hline $2-3$ years & 3 \\
\hline
\end{tabular}

Hence maximum anemic children were under 1 year of age. This result was in consistent with study done by Nadia Roumeliotis in their article titled Vitamin B12 deficiency in infants secondary to maternal causes which showed that infant $\mathrm{s}$ Vit B12 levels is related to maternal Vit b12 levels via neonatal stores at birth and amount in breast milk. ${ }^{[3]}$ Also in study conducted by Honzik $\mathrm{T}$ et al in the year 2010 it was concluded that average age of diagnosis of Vit B12 deficiency anemia was 4 months ${ }^{[4]}$.

On clinical examination 18 children had development delay, 17 out of 25 children had infantile tremor syndrome, this is in consistent with the study done by Honzik $\mathrm{T}$ et al titled Clinical presentation and metabolic consequences in 40 breast fed infants with nutritional Vit B12 deficiency- what have we learned?. In their study the percentage of babies with varied clinical presentation in Vit B12 deficiency were as follows: ${ }^{[4]}$

\begin{tabular}{|lc|lc|}
\hline Failure to thrive & 48 & \multicolumn{2}{|l|}{ Developmental delay 38} \\
\hline Hypotonia & 40 & Microcephaly & 23 \\
\hline
\end{tabular}

In MRI studies 15 out of 25 cases had cerebral atrophy accounting for $60 \%$ cases. Out of these 15 cases 14 cases had picture of dimorphic anemia on PBF. This result is comparable to the study done by Karl -olof lovblad titled Retardation of myelination due to dietary Vit B12 deficiency: cranial MRI findings. MRI findings in 14.5 months old baby with psychomotor retardation and strict vegetarian parents revealed severe brain atrophy and retarded mylenation frontal and temporal lobe most affected. ${ }^{[5]}$

Also study done by Chiara Briani titled Cobalamine deficiency: clinical picture and radiological finding revealed that MRI in such children showed loss of white matter and delayed myelination ${ }^{[6]}$. Similarly study done by Nadia Roumeliotis showed that MRI changes in vit B12 deficiency children showed enlargement of lateral and third ventricle, subarachnoid space enlargement consistent with atrophy and microcephaly. ${ }^{[3]}$

\begin{tabular}{|l|l|l|}
\hline $\begin{array}{l}\text { Present study MRI } \\
\text { changes in anemic } \\
\text { children }\end{array}$ & Cerebral atrophy & \\
\hline Karl -olof lovblad & $\begin{array}{c}\text { severe brain atrophy and } \\
\text { retarded mylenation } \\
\text { frontal and temporal } \\
\text { lobe most affected. }\end{array}$ & consistent \\
\hline Chiara Briani & $\begin{array}{c}\text { loss of white matter and } \\
\text { delayed myelination }\end{array}$ & consistent \\
\hline Nadia & $\begin{array}{c}\text { subarachnoid space } \\
\text { enlargement consistent } \\
\text { with atrophy }\end{array}$ & consistent \\
\hline
\end{tabular}

Table 1: MRI Showing Cerebral Atrophy and Dilation of Ventricles

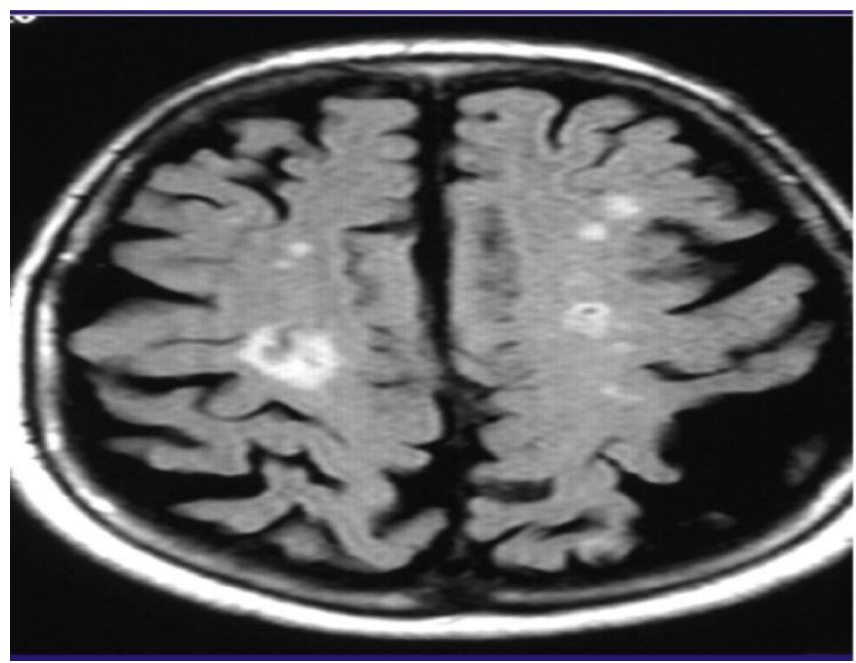


Table 2

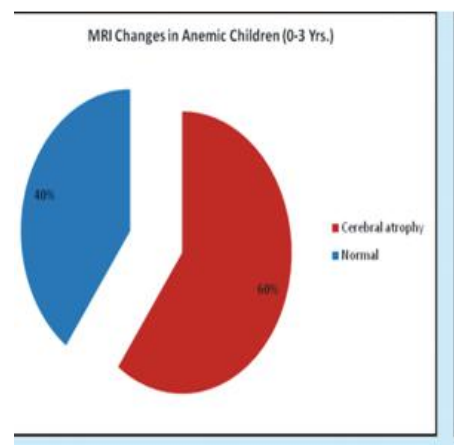

Table 3

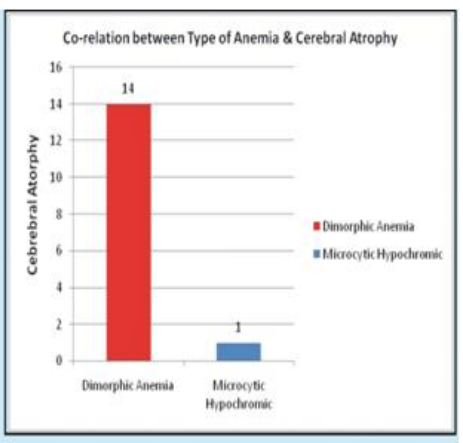

6. Briani C., Torre DC., Citton V., Manara R., Pompanin S., Binotto $G$ et al. Cobalamine deficiency: Clinical Picture and Radiological Findings. Nutrients. 2013Nov;5(11):4521-39.

\section{Conclusion}

Cerebral atrophy was found in $60 \%$ of severely anemic children. And $56 \%$ of total Vit B12 deficient severely anemic children had cerebral atrophy.

\section{Bibliography}

1. Tulika Seth. Hematological disorders. In:Ghai Essential Pediatrics. Vinod KP; Arvind Bagga; Aditi Sinha. $8^{\text {th }}$ edn. 2013;12:330-31.

2. Norma B.Lerner. Vitamin B 12( Cobalamine) deficienc. In: Nelson Textbook Of Pediatrics. Kliegman; Stanton; St Geme; Schor. $20^{\text {th }}$ edn 2016;454.2:2321.

3. Roumeliotis N., MD, Dix D., MB, Lipson A., MD. Vitamin B12 deficiency in infants secondary to maternal causes. CMAJ.2012Oct2;184(14):1593-98

4. T Honzik., M Adamovicova., V Smolka., M Magner.,E Hruba., J Zeman. Clinical presentation and metabolic consequences in 40 breast fed infants with nutrional vitamin B12 deficiency- what we have learned?. Eur J Pediatr Neurol. 2010 Nov;14(6):488-95.

5. Lovbland K., Ramelli G., Remonda L., Nirkko AC., Ozdoba C., Schroth G. Retardation of myelination due to dietary vitamin B12 deficiency: Cranial MRI findings. Pediatr. Radiol.1997;27:155158.doi:10.1007/s002470050090.[Pub Med][Cross Ref]. 